Final published version: Almeida, S.N., Elliott, R., Silva, E.R., \& Sales, C.M.D. (in press). Fear of cancer recurrence: A systematic review and meta-synthesis of patients'

experiences. Clinical Psychology Review. (C2018 Elsevier. This is an author final version and is not the version of record.

\title{
Fear of cancer recurrence: \\ A systematic review and meta-synthesis of patients' experiences
}

\author{
Susana N. Almeida \\ Portuguese Institute of Oncology of Porto FG, EPE; ISMAI - University Institute of \\ Maia, Portugal \\ Robert Elliott \\ Counselling Unit, School of Psychological Sciences and Health, University of \\ Strathclyde, Scotland \\ Eunice R. Silva \\ Portuguese Institute of Oncology of Porto FG, EPE, Portugal \\ Célia M. D. Sales
}

Centre for Psychology at the University of Porto, Faculty of Psychology and Education Science at the University of Porto (FPCEUP), Portugal

Corresponding author: Susana N. Almeida. Postal address: Rua Dr. António Bernardino de Almeida, 62 - 4200-162 Porto, Portugal. Tel.:+351 225084000. E-mail address: salmeida@ipoporto.min-saude.pt

\begin{abstract}
Fear of cancer recurrence (FCR) is a significant issue for most cancer survivors, which is now extensively confirmed by the scientific literature in the psycho-oncology field. We aimed to further explore the experience of having FCR from the point of view of patients by systematically reviewing qualitative studies. Following PRISMA guidelines, 64 qualitative studies were selected. All participants' quotes about FRC were identified, then analysed using a conceptual framework based on the emotion-focused therapy theory of emotion schemes, which consist of experienced/implicit emotions, along with perceptual-situational, bodily-expressive, symbolic-conceptual and motivationalbehavioral elements. FCR was found to be an intense, difficult, multi-dimensional experience. According to participant descriptions, FCR resembles a trauma-like phenomenon, including forms of re-experiencing, avoidance, negative thoughts and feelings, and arousal or reactivity related to cancer-related triggers or memories. Vivid metaphors expressing vulnerability and conflict also reflect the strong impact of FCR in patients' lives. Implications for psychotherapeutic work are discussed.
\end{abstract}




\section{Highlights}

- Qualitative data complement and can expand our current knowledge about fear of cancer recurrence.

- FCR is described qualitatively by patients as a complex experience involving emotional, perceptual, conceptual, bodily and behavioral dimensions.

- FCR is a post trauma-like phenomenon: it is an intense and extensive experience; it has a flashback-like quality in which painful episodic memories related to cancer return repeatedly; it is described through vivid metaphors of conflict and vulnerability that emphasize fragility and helplessness.

- Humanistic-experiential therapeutic approaches might be considered for treating maladaptive FCR, which needs further investigation.

Key-words: cancer, fear of cancer recurrence, qualitative, emotion schemes, systematic review

\section{Fear of cancer recurrence:}

\section{A systematic review and meta-synthesis of patients' experiences}

\section{Introduction}

Metaphorically identified as the Sword of Damocles, fear of cancer recurrence (FCR) is defined as the "fear, worry, or concern relating to the possibility that cancer will come back or progress" (Lebel et al., 2016, p.3266). It has been found to some degree in $73 \%$ of cancer survivors (Simard et al., 2013). To a certain extent, this fear is an appropriate and normal response to the real threat of cancer and cancer treatments (Herschbach \& Dinkel, 2014). However, when certain features are present, such as recurrent and long-lasting images or thoughts about cancer or death it often proves difficult to control and causes significant distress (Mutsaers et al., 2016). Thus, fear of recurrence can become dysfunctional, affecting people's well-being, quality of life, and emotional and social functioning (Cancer Australia, 2011; Herschbach \& Dinkel, 2014) and in many cases needing clinical attention.

Due to its relevance and clinical implications for cancer patients, there is growing research on FCR and by now there are already several systematic reviews of quantitative data about FCR, including prevalence, course over time, determinants and consequences (Crist \& Grunfeld, 2013; Simard et al., 2013). In addition, there have been reviews of theory (Fardell et al., 2016; Simonelli, Siegel, \& Duffy, 2016), assessment (Thewes et al., 2012), and intervention (Sharpe, Thewes, \& Butow, 2017). Drawing on these reviews, it can be said that FCR is a major concern for many people with cancer, tends to be stable over time, is more associated with being younger and having more (and more severe) physical symptoms, and can impact negatively in psychological, functional and quality of life domains (Simard et al., 2013). In terms of theoretical orientations, the cognitive-behavioral paradigm is the most common formulation for understanding and developing interventions to help people dealing with FCR (Fardell et al., 2016).

Although there is a predominance of quantitative studies, qualitative research about FCR has also been conducted, aiming to explore people's experiences of the possibility of recurrence, including the specific contents of their worst fears, their coping strategies for dealing with FCR, or what might distinguish higher from lower levels of FCR (e.g. Mutsaers et al., 2016; Thewes, Lebel, Seguin Leclair, \& Butow, 2016; Vickberg, 2001). Seeking to understand how people see things (Taylor, Bogdan, 
\& DeVault, 2016) qualitative research is an interpretive, naturalistic approach to peoples' world (Denzin \& Lincoln, 2017) that gives voice to participants' own experiences. Qualitative information seems thus particularly important for thorough understanding of the phenomenon of FCR and fundamental for informing psychotherapeutic practices. Recognized as essential for assessing and improving the quality of health care services (NICE, 2012b), patient's view brings alive the patientcentered model of care (Mead \& Bower, 2000) where the patient is an active and autonomous agent who participates in decision-making processes about their illness and its management (Kaba \& Sooriakumaran, 2007; Longtin et al., 2010). The patients' expressed feelings, concerns, and experiences during an illness also facilitate a deep understanding of how it affects the person as a whole human being (physical, emotional, social, spiritual) (Hall, Kunz, Davis, Dawson, \& Powers, 2015).

When we began this review, we couldn't find any comprehensive systematization or synthesis of qualitative data on FCR that could contribute to current discussions and developments about it. Guided by the main research question, "What is fear of cancer recurrence for people who experience it?" our aim was to review, interpret and synthesize the existing qualitative data about the FCR experience.

\section{Method}

\subsection{The researchers}

Our research team was composed of two clinical psychologists who have worked in a cancer hospital for about 13 years (SNA and ERS) and two university professors, one mainly a researcher (CS) and the other a clinical practitioner, researcher and teacher (RE). Three of the researchers are Emotion-Focused Therapy (EFT) therapists (including one of the developers of EFT) and one (CS) is a family therapist.

\subsection{Search strategy}

A systematic search was conducted in April 2016 using the electronic databases PsycInfo, PubMED and CINAHL in order to find qualitative research on FCR. The search key-terms were "fear/anxiety/worry" combined with "recur*/relapse/coming back/progress" and "cancer/neoplasm". Additional searches were done through grey literature, "snowballing", journal hand-searches, review-level material (NICE, 2012a) and "berrypicking" strategies (Bates, 1989), in order to find additional relevant studies. We did not limit our search temporally, and maintained a Google Scholar search alert until end September 2016.

\subsection{Selection strategy}

The selection of studies was guided by the following inclusion criteria: 1) qualitative and mixed method studies about FCR or about wider topics containing this particular issue (such as "survivors' experience"); 2) concerning adult cancer patients; 3 ) presented in scientific articles or dissertations; and 4) written in English, French, Portuguese or Spanish. We used a broad definition of cancer survivor, considering the person from the time of diagnosis until the end of life (NCI, n.d.). Accordingly, we did not distinguish "survivor" and "patient" terms and will use both interchangeably throughout.

Figure 1 presents the PRISMA diagram showing the steps followed from the initial identification of the studies to the 64 final studies. Each step was completed by two of the researchers (SA and ES); the other members of the team participated in the decisions related to the final phases of eligibility and inclusion. Covidence, a Cochrane software tool for systematic reviews (www.covidence.org) was used to assist the review 
steps since the importation of citations after the databases searches to the selection of the studies to be included in the final analysis.

This review was registered at PROSPERO International prospective register of systematic reviews in April 2016 (PROSPERO 2016:CRD42016036688 Available from http://www.crd.york.ac.uk/PROSPERO/display_record.asp?ID=CRD42016036688).

\subsection{Quality appraisal}

When developing a qualitative meta-analysis, the quality appraisal of the studies informs the choice of the studies for the meta-synthesis, helping to make inferences, analyze and take conclusions from the data retrieved (Timulak, 2009). In the present review, the quality appraisal of the studies was done using a Quality Appraisal Form, adapted from the Publishability guidelines for qualitative research, developed by Elliott, Fischer, \& Rennie (1999). Fourteen criteria were included, from which seven are considered pertinent to both qualitative and quantitative approaches and the other seven especially pertinent to qualitative research (Elliott et al., 1999). Every criterion was assessed as "appropriate", "inappropriate/insufficient" or "not reported". Each study was classified as having "high quality" $(++)$, when all or most criteria were rated as appropriate or where even if insufficient, the conclusions were very unlikely to change; as "moderate/sufficient quality" $(+)$ when some of criteria were rated as appropriate or where insufficient or not reported, the conclusions were very unlikely to change; or as "low/insufficient quality" (-) when few or no criteria have been fulfilled or the conclusions were likely or very likely to change due to the criterion not being met (NICE, 2012a). Only the studies rated as "high" or "moderate/sufficient" quality were included in the analysis. The studies' evaluation was done by one judge who rated the totality of the studies (SNA) and a second judge who provided a credibility check rating half of the studies (ERS). The interrater reliability for the quality judgements was of $\mathrm{k}=0.848$, which is considered a strong agreement (McHugh, 2012). None of the 64 studies selected proved to have "low/insufficient quality"; thus all were included in next phases.

\subsection{The selected studies}

Sixty-four (64) studies were included in the qualitative synthesis, mostly qualitative studies $(94 \%)$ presented in articles $(84 \% ; 16 \%$ dissertations). The main methods used for data collection were individual interviews (72\%), frequently semistructured and in-depth, and focus group interviews (17\%). Together, the studies included a total of 1727 participants, with a range between 1 author reflecting upon his personal experience (Horlick-Jones, 2011), and 360 cancer patients who answered an on-line open question about their worries (Cesario, Nelson, Broxson, \& Cesario, 2010). In more than half of the studies $(53 \%)$, the participants had had breast cancer; another $25 \%$ of the studies included mixed cancer diagnosis. Although different continents Europe, North and South America, Asia and Australia - and different countries were represented, about $40 \%$ of the studies were originally from the United States of America. Years of publication ranged from 1992 to 2016, with more than half of the studies having been published between 2010 and 2016. Table 1 presents more detailed characterization of the selected studies.

Concerning the quality of the studies, the majority (about $84 \%$ ) was considered as having "high quality". The criteria "owning one's perspective" (criterion 8), "providing credibility checks" (criterion 11) and "accomplishing general versus specific research tasks" (criterion 13) were the most critical aspects contributing for the lower assessments. In line with our leading interest of capturing patients' experiences on FCR, 
we decided to use for analysis exclusively the quotes from participants, as every selected study met the criterion "grounding in examples" of the Quality Appraisal Form (criterion 10).

\subsection{Data analysis}

Considering the diversity of the selected studies regarding FCR, initially the research team roughly divided two sets of studies: 1) studies in which FCR was a primary focus or one major result and was extensively discussed $(n=8)$, and 2$)$ studies in which FCR was one of the topics or emerging themes, but not a main or exclusive issue of the study $(\mathrm{n}=56)$. The analysis began with the first set of studies, from which the first themes were derived. Secondly, the information of the second group of studies was fit in the categories already defined, which were checked and adjusted whenever necessary.

Having previously determined to do a grounded theory analysis (Strauss \& Corbin, 2008) in order to produce the meta-synthesis, the team adopted the Emotion Scheme framework (ES; Greenberg, Rice, \& Elliott, 1993) to organize the data, considering its apparent suitability and in consonance with the research team's assumption that FCR is mainly an emotional experience (Almeida, Silva, Sales, \& Elliott, 2016).

An Emotion Scheme is a complex self-organizing process that involves different domains of experience - perceptual-situational, bodily-expressive, symbolic-conceptual, motivational-behavioural - organized around a particular experienced or implicit emotion (Elliott, Watson, Goldman, \& Greenberg, 2004). According to EFT theory, emotion schemes are the primary implicit source of experience, producing automatically felt experiences and action tendencies (Greenberg \& Watson, 2006). The elements of an ES discriminate complementary and interconnected information about a particular emotional experience, enabling us to separate out how people perceive, feel, embody, make sense of and act about FCR. We found this underlying framework to be a useful yet not overly constraining structure to support our grounded theory analysis (Strauss \& Corbin, 2008). In addition to being a specific theoretical feature of EFT theory, the ES framework comprises common aspects from most psychological theories, such as cognitive, emotional, bodily, narrative and behavioural aspects of human experience; thus it proved helpful not only to deep knowledge about FCR experience but also to inform psychotherapeutic practice.

After repeatedly reading the data, the extracted material was analyzed "line-byline" (Strauss \& Corbin, 2008), and different meaning units were identified, ranging from single words to complete sentences or paragraphs, which could be attributed to a specific ES domain (experienced/implicit emotion; perceptual-situational, bodilyexpressive, symbolic-conceptual and motivational-behavioral). Then, within each ES domain, the quotes of the participants were progressively grouped according to same or similar meaning, creating different categories and later higher and lower-order categories. At the end of the categorization process, it was possible to find some unique meaning units that couldn't be grouped with any others and which were therefore excluded from the final analysis and later synthesis. This process was done by the first author and then carefully audited, discussed and revised step by step with one of the other researchers (RE), a specialist in both EFT theory and grounded theory analysis.

\section{Results}

In relation to our research question, What is fear of cancer recurrence for people who experience it, we found it helpful to further differentiate some of the emotion 
scheme elements into subdomains (see Figure 2): 1) different expressed or implicit emotions; 2) trigger-situations that elicited FCR; objects of fear; narrative elements related to when, how long and how FCR emerges and related episodic memories (ES perceptual-situational domain); 3) bodily expressions of the different emotions (ES bodily-expressive domain); 4) metaphors of FCR, distinct dimensions of mental activities and cognitions and meta-cognitions about FCR (ES symbolic-conceptual domain) and 5) action tendencies related to FCR (ES motivational-behavioural domain). We next present each of these themes, using illustrative quotes from participants.

\subsection{Emotions associated to the experience of fearing cancer recurrence}

The dominant emotion of the experience of FCR was, as expected, fear. Participants described fear by several different terms, using the word "fear" itself (or "being afraid") or synonyms such as "anxiety", "worry", "scared", or "dread". In reading the excerpts, we noticed that the fear was mostly defined by expressions of great intensity: "pretty strong fear", "horrible fear", "real frightened", "big dread", "scared the hell out of me", "very worried", "terrified", "panic", which were much more common than "apprehensive" or simply "nervous". We also included in the emotion of fear the feelings of insecurity, uncontrollability and uncertainty reported by some participants: "had no sense of security" (Fang \& Lee, 2016); "I feel very exposed" (Brooks, Poudrier, \& Thomas, 2014); "I don't have control over it", "always walking with uncertainty" (Berman, 2013). Blended fearful states were also detected, particularly fear and surprise, as expressed by "fright", and fear and disgust, as expressed by "horror".

Another set of accompanying emotions was labelled as depression, in which we included feelings of "sadness", "loss", "grief", "alone" and feeling "set apart" or "abandoned" but also descriptions of feeling "more vulnerable", "weaker" as well as being "helpless" and with "no hope" or having "no power about it".

General distress or undifferentiated states were other emotions found, probably connecting either to fear, sadness or more confusing or unclear states: "extremely stressful", "distressing", "painful", "hard", "very difficult", "dramatic", "devastating", "so many feelings", "freaked out", "messed up".

Positive or pleasant emotions appeared as well in participants' reports about FCR, namely when talking about getting out a fearful state. Participants described being "relieved", getting "more confidence", feeling "reassured" or comforted after good news: "Well, the test showed nothing. There was nothing there, which was very comforting...." (Berman, 2013). Feelings of gratitude were also described when referring to past or present cancer experiences: "I was lucky this time" (Vickberg, 2001); "I am thankful that I have a next day" (Cesario et al., 2010). Acceptance was another emotional state referred as opposed to fear: "I've gotten some peace of mind, too, from the acceptance. I don't have the same level of anxiety" (Berman, 2013).

The emotions of anger, shame/guilt and surprise were also referred by some participants: "I am just angry at my body, it let me down." (De Vries, Den Oudsten, Jacobs, \& Roukema, 2014); "I am working way too much and what if I had a recurrence? I should be spending this weekend with [my children]. And then that just kind of unfolds because you feel guilty and you start thinking about death." (Berman, 2013); "It preoccupies me a lot and that surprises me." (Mikkelsen, Søndergaard, Jensen, \& Olesen, 2008).

\subsection{Trigger-situations that elicit fear of cancer recurrence}


Noticing something in the body was one of the most referred-to triggers for FCR, whether it was a pain or other physical symptom: "Every little pain or lump on your body" (Jones, 2012) or a difference in the body related to cancer experience: "your breasts just don't feel the same because the way they construct it with the muscle or insert, you can feel all that. They just don't feel like natural breasts. It's just another trigger" (Berman, 2013). Waiting for a medical exam or appointment (even in the waiting room), particularly to receive the results of medical tests, was another common identified situation: "But when I really start to think about it is when I have to do scans" (Jones, 2012); "Just sitting in that room [waiting for the check-up]" (Raymer, 1993). Encountering reminders such as hearing, talking or reading about cancer (in $\mathrm{TV} /$ newspaper/magazine or by other people), just thinking about it or remembering the experience of having had cancer or treatment were also identified triggers of FCR: "when I see people in my village dying because of these diseases even years after treatment" (Saraf, Singh, \& Khurana, 2013); "God, it makes me scared just thinking about it now" (Scott, 2014).

Other situations people described as activating FCR were both being in some kind of treatment (such as daily hormone therapy or taking pills for pain) and being off treatment ("not having that 'safety net' of treatment", Arnold, 1999). Finally, being under stress or engaging in risky behaviours was a trigger for some: "They say that stress is a trigger for getting cancer. So, it's like every stress has extra stress with it" (Berman, 2013); "I haven't been eating properly, and I have been smoking and shouldn't be smoking at all..." (Raymer, 1993).

\subsection{Objects of fear}

It was possible identify different objects of fear, when people referred to FCR. The reoccurrence of the same cancer or of a different one (and even of a different serious illness), the spreading of cancer and the fear of the cancer "still being there" were directly expressed by participants, as well as fear of cancer itself. Death as a main concern was also identified, frequently associated with not wanting to leave family, especially children: "I don't survive it and die, and then my kids are left without a mother" (Siegel, Gorey, \& Gluhoski, 1997). Other fears related to doing treatments again, feeling weak, suffering or having a diminished quality of life, including being dependent and having physical limitations: "It worries me that if comes back, it's going to be stronger" (Berman, 2013); "I think the worst for me was if they find the cancer again, would I have to go through the chemotherapy treatments again?" (Raymer, 1993). Fear of the future, of planning ahead, and more generally fear of uncertainty, were described as well. Some patients referred likewise to worry about the worry itself: "Sometimes I worry that the worry is going to grow" (Berman, 2013).

\subsection{Narrative elements related to when, how long and how FCR emerges}

Narrative elements were often observed in participants' discourse, although this information was quite heterogeneous across studies and participants. It is possible to describe it though in terms of continuums of frequency and of time-duration of the experience of FCR, as follows. The presence of FCR ranged from "always present", "every day", "constant" to "occasionally" or "intermittent". For some patients, it was only present on specific occasions (as reported above in Trigger-situations), or at specific moments of the day, frequently at night, especially during quiet times, while trying to relax or sleep, and in the morning, when waking up. Others described it as appearing "suddenly" or "out of the blue": 
- "Sometimes I'll think more about that, but sometimes it's just 'that" (Berman, 2013).

- "There are times still when I wake up (...) before I am completely wide awake and I don't want to get up." (Raymer, 1993)

- "On the nights that I wake up, or I can't get back to sleep" (Flynn et al., 2010).

We can also locate the emergence of FCR along a chronological line, in relation to the cancer diagnosis event. Although for some people this fear has been presented "since ever", even before diagnosis, for most, FCR emerged at the point of the cancer discovery, after the treatment ended, or around 5-year mark (for some others it was associated to a certain event, as someone's death from cancer): "From the moment I was told I had cancer in my body" (Crouch \& McKenzie, 2000).

Regarding its duration, FCR appears to be episodic, and can be present "for 10 seconds there" (Berman, 2013) to "a good part of the day (...) six hours maybe" (Mutsaers et al., 2016).

\subsection{Episodic memories related to FCR}

Specific episodic memories were evoked when people talked about FCR (whether asked directly or not), especially related to the different stages of the illness trajectory: around cancer diagnosis, situations during the period of treatment, check-ups situations, and episodes after the cancer experience:

- "They say you never forget the day you find your lump and it is true. It was last year...and it was Mother's Day (...) I said I bet it is malignant." (Raymer, 1993);

- "It was a hard go at first. The morning I went into the hospital, my husband was there and my daughter and I can remember going into the operating room and when I came out, they were there." (Thomas-Maclean, 2001);

- "I suppose the thing that always sticks in my mind was he [doctor] said it was incurable, but treatable" (Kelly \& Dowling, 2011).

Remembrances of past situations previous to cancer diagnosis were also reported, including childhood memories such as the first recognition of mortality: "I remember the first time I thought 'someday I am going to die' and it scared me and I sat up in bed and I remember just yelling for my mom" (Sadler-Gerhardt, 2007). Other remembered situations concerned or included others, such as conversations with doctors/nurses, others' reactions to his/her illness or relatives/friends/others having and/or dying with cancer.

\subsection{Bodily expressions of fear of cancer recurrence experience}

In this category, we identified primarily expressions of fear and expressions of depression. Examples of bodily expressions of fear are "shiver" (Raymer, 1993), "shaking" (Berman, 2013), "get tense" (Saraf et al., 2013) and "um frio na barriga" (literally, "a chill in the belly"; Salci \& Marcon, 2010). People also described FCR as "nerve-racking" (Thompson et al., 2010), "ficava igual uma corda de violão, bem esticada" (It was like a guitar string, stretched tight; Salci \& Marcon, 2010), "I am just a bunch of nerves (...). And I get pains in other places in my body" (Raymer, 1993), "I walk around with nerves on edge" (Grimsbø, Finset, \& Ruland, 2011).

"Crying" was the most presented physical expression of sadness; other examples of depression and sadness are "my hearts sinks" (Saraf et al., 2013) and "aquele aperto no coração" (tightness in the heart; Salci \& Marcon, 2010).

We also identified general body expressions as "it's in my bones"; "That feels to me like hurt. That feels to me like pain"; "I'd be taking it so far, to the point where I'd physically feel sick about the whole thing" (Berman, 2013); "It probably does do weird 
things to your body" (Raymer, 1993). Specific expressions related to head/mind were recognized as well: "você fica com a cabeça "perturbadinha" (disturbed head; Salci \& Marcon, 2010); "I usually feel it in my brain"; "dullness of my thinking" (Berman, 2013).

Physically-expressed laughter was found in different interviews, and we considered it as probably expressing different underlying feelings - sometimes was expressed when people were talking about worry, seeming to be a nervous laughter; other times it looked more related to underlying anger (as when someone described feeling annoyed for having been, has one participant said, "false-advertised" in relation to the end of treatment).

\subsection{Fear of cancer recurrence metaphors}

Sets of metaphors were diverse but we grouped as much as possible under similar ideas or meanings. We found a root metaphor (Elliott, 2006) about FCR that we called Risk and Danger, under which we distinguished the following different subthemes, for which we provide some examples:

- Being in a war: "I feel under attack again" (Horlick-Jones, 2011); "like a sword hanging over my head" (McLoone et al., 2012); "feeling like maybe a bomb is going to go off anytime inside our body" (Kvale, Meneses, DemarkWahnefried, Bakitas, \& Ritchie, 2015);

- Adversarial situations: "It is like the bad guy and the good guy. I would say, yeah you are out there, but let's you know ... let's have a fencing match, you know, let's get out the duelling pistols ... so I would be willing to put up a battle..." (Raymer, 1993);

- Guarding Against Attack: "I feel like if I am caught off guard it will sneak round the edges ... I'm always waiting for it to come back" (Balmer, Griffiths, \& Dunn, 2015); "Now I feel like the rest of my life is spent fighting and looking over my shoulder" (Miller, 2015);

- Being Attacked by Monsters: "It basically means just a deep-seated kind of boogie monster that could resurface again"; "like a little ghost that hunts you" (Berman, 2013).

This first set of metaphors can be grouped together as FCR Is Conflict. Another set of metaphors revealed qualities of the experience of FCR, such as being a controlling entity, frequently under the surface and that makes people feel vulnerable/insecure and injured/ill:

- A Controlling Entity: "it (FCR) absolutely controlled my life. Totally. Totally overshadowed it and totally controlled my life" (Scott, 2014);

- Under the surface: "But it's lurking, it's like anything really that's troubled you for a long time, hidden away in the back there, somewhere, it'll pop up every now and again" (Scott, 2014); "it's like an undercurrent in your life" (McLoone et al., 2012);

- Vulnerability/Insecurity: "Until something's happened, we all operate under this false sense of security. But once something has happened, like this, it's kind of like, the bubble's been burst. We realize that something could happen, because it has" (Cohen \& Ley, 2000);

- Injury/Illness: "It can become almost crippling if you let it"; "The worry undermines that things will always work out" (Berman, 2013). This second set of metaphors can be grouped together as FCR Is Vulnerability. 


\subsection{Dimensions of mental activities: the degrees of certainty, the verbal tenses and the sensorial pathways}

The most common and general mental activity identified was thinking, either presented as an active reflective process: "When I think of recurrence, I really think of dying" [emphasis added] (Berman, 2013); or as a passive process, indicated by sentences as "the first thing that comes to my mind is cancer" or "because it brings the fear running in my head" [emphasis added] (Berman, 2013).

Exploring the other mental activities described by participants, we could identify different layers or axes that can be related to each other, which we named as: degrees of certainty; verbal tenses/time line and sensorial pathways (see Figure 3). Knowing and not knowing seemed particularly relevant in participants' discourses, revealing the poles of the continuum degrees of certainty, which included other mental activities such as supposing, wondering or believing: "You don't know if you're gonna live through it or not" (Mutsaers et al., 2016); "Now I guess I know it's something that can betray you without you even knowing what's going on" (Thomas-Maclean, 2001). We also identified mental activities reflecting change processes derived from FCR, such as realizing, making sense, understanding, being aware or acknowledging: "This made me realize that I will die - not maybe — but I will die!" (Berman, 2013).

Crossing this axis with the verbal tenses/time line, we realize how different mental activities may connect with past (as remembering), present (as in noticing) or future (as in expecting). We've also noticed a preponderance of subjunctive grammatical modes and interrogative forms, probably reflecting the uncertainty and doubts evoked by the fear of cancer recurring, but interestingly for some participants the cancer recurrence was assumed as inevitable and in these cases, present and future tenses were used:

- "Oh what if she finds it, it's just going to change everything...I'd have to stop work again. I'd have to rearrange finances" (Jones, 2012);

- "Will the next test bring me to more treatment? The length of time I have left to live, will treatment keep me from working? How will I have health insurance if I don't work? Will my illness leave my husband in debt? What will dying be like? Will we have to move from our remote mountain town home? Will I be able to leave my husband with enough money to survive?" (Cesario et al., 2010);

- "My question is not if it's coming back...It's when" (Allen, Savadatti, \& Levy, 2009).

Different sensorial pathways could also be intersected with the other two axes: verbal and auditory sensory channels seemed to relate to "if" statements and questioning, as well as with conditional verbal tense; somatic (as in feeling) usually reflects present statements and visual-perceptual channel, depicted in verbs as imagining, noticing or remembering, seems somehow traverse the whole time line: "I almost feel as if it's inevitable" (Mutsaers et al., 2016); "I imagine ... that maybe it [recurrence]... it may be the end ... may be the end and ... that this would take you" (Raymer, 1993).

\subsection{Cognitions and meta-cognitions about FCR}

Regarding what people reflected about FCR, we could find contents related to the internal, psychological process of fearing and meta-cognitions about FCR. Two different participants explained their internal process as follows:

- "[There were] two halves ... on the one side of the balance there was the fear of enjoying life because of the other side of the balance which was the possibility of recurrence ... This is like a step along the way: that I might be able to actively 
enjoy life on that side of the balance. On the other side of the balance is the fear of recurrence, and after that — death." (Raymer, 1993);

- "I call it fear because it was paralyzing. There was something that was paralyzing to me, and I can only think of it as fear because it was this. And I don't know what I was afraid of. Was I afraid of being sick again? I don't know what I was afraid of...maybe it wasn't fear of recurrence. Maybe I was confident that the cancer would come back, but not being at peace with it? Or not being accepting of it?" (Berman, 2013)

Some meta-cognitions about FCR revealed opposite ideas about FCR, such as it being "not an irrational fear" versus being "totally irrational" (Berman, 2013) or "it is just a fleeting thought" (Shachar Siman-Tov, 2008) versus "I was obsessed with recurrence" (Scott, 2014).

\subsection{Action tendencies related to FCR}

Two chief and opposing action tendencies were identified concerning FCR: avoiding and approaching, and within each, we could find aspects related to illness/treatment/death, to self-experience, and to others.

Avoiding. Concerning illness/treatment/death avoidance, participants referred not wanting to do treatments or live with cancer again and also not wanting to die with cancer. Avoiding medical examinations, disregarding bodily changes, believing doctors can prevent a recurrence or simply hoping cancer is not coming back were some other desires, wishes, intentions and action tendencies identified:

- "I wouldn't do the chemo again, I wouldn't do it again" (Thewes, Lebel, Seguin Leclair, \& Butow, 2016);

- "This is not how I want to die" (Berman, 2013);

- "I hope that my cancer doesn't come back so I can retire and so my wife and I can travel and see the world" (Jones, 2012).

Avoidant self-related action tendencies included mainly trying not to think, talk or hear about FCR, wanting to put it aside or out, forget it, distract from it and avoid it. Wanting to say "it's over" or get beyond cancer, wanting to keep normalcy but also not wanting to make long-term plans were other self-experiences:

- "Well, I think you just try to put them [anxieties] to one side as much as you possibly can. I don't let it destroy my day, constantly thinking "oh my God, it's going to come back tomorrow". I don't think like that, I try to put it out of my mind, keep busy, do interesting things, whatever" (Scott, 2014);

- 'I wish that I just broke a bone and it's reset and I'm all healed now and I can close the door, like desperately I want to close the door, but I feel like I can't because it is not over" (Berman, 2013).

Keeping FCR to oneself or isolating oneself, not wanting people to feel sorry for them and the need to be independent and to not be a burden to the family were otherrelated avoidant behaviours or motivations: "I have never said that to anybody" (SadlerGerhardt, 2007); "I didn't tell them [family] anything about the cancer probability because I didn't want them to be worried" (Mehrabi, Hajian, Simbar, Hoshyari, \& Zayeri, 2016).

Approaching. Several participants heard FCR as impelling them to do something in order to feel some control over a possible recurrence, particularly self-care through changing food habits and exercise, monitoring and paying attention to body signs, or preparing somehow for a recurrence: 
- 'I'm doing it, because it makes me feel like I have some control and that wards off the worry. I guess my whole strategy is that in order not to worry, I do something." (Berman, 2013);

- "So, I started on this watching what I eat. Not necessarily a diet, just eating correctly what I'm supposed to eat, my vegetables, my fruit ..." (Kvale et al., 2015);

- "Just checking myself over to make sure there is nothing new." (Taylor, Richardson, \& Cowley, 2011).

Fighting or planning to fight against a future cancer recurrence was another action tendency described: "I sure as hell would give it [recurrence] a fight, ha ha. I would fight, you know ... I would not accept death you know... I wouldn't just lay back and say all right, you know, I am going to die." (Raymer, 1993);

Underneath FCR, another need was identified for participants, the need to accept, deal or recognize their mortality and ultimately prepare for their own death:

- "Then you have to learn to ... I guess deal with the question... How can I put it? Of then really learning to accept the fact that, you know, to accept death" (Raymer, 1993);

- "How do I want to leave things? How do I want my family to perceive me?" (Berman, 2013).

Regarding self-experiences, we recognized self-talking, mainly self-coaching and self-assurance, the need to deal or live with FCR, but also the wanting to live and appreciate life better. We also included in this sub-theme spirituality, expressed by having faith and praying. Here are some examples:

- "I can kind of, you know, calm myself down, this kind of thing." (Cohen \& Ley, 2000); "Because I just tell myself I'm not going to worry about it. If it happens, it happens. Deal with it then." (Thomas-Maclean, 2001);

- "And I just want to live my life. I want to live it as fully as I can." (Shachar Siman-Tov, 2008).

Sharing their experiences with others, talking about FCR and receiving comfort and help from others (including in therapy) were other helpful approaching strategies people described when dealing with FCR:

- "When I have a fearful moment I tell my brothers, sisters and partner that I am worried." (De Vries et al., 2014);

- 'Another cancer survivor telling me 'it's okay, don't worry', would be such a great comfort and I wouldn't feel scared anymore." (Wang et al., 2016)

We also found combined action tendencies, holding awareness of approaching and avoiding at the same time, in the discourse of some participants, as seen in the following examples:

- "Sometimes I just try to ignore it. Sometimes I tell myself it's already there and there's not much I can do but just to face it..." (Raymer, 1993);

- "Just by having this kind of attitude, confronting breast cancer and the fear it's evokes, and at the same time letting go, and surrendering kind of approach." (Shachar Siman-Tov, 2008).

Finally, FCR was described as paralysing or blocking any action tendency: "I was just so paralyzed by fear" (Berman, 2013); "it's just almost crippling” (Mutsaers et al., 2016).

\section{Discussion}


The purpose of this qualitative meta-synthesis was to bring together what is known about the experience of fear of cancer recurrence, using cancer patients' described experiences. Based on our analysis and synthesis, FCR is a complex, intense and difficult human experience involving different emotional, perceptual, mental, bodily and behavioral aspects. Our findings consolidate some previous knowledge on FCR, such as the importance of certain triggers that elicit FCR, specific objects of fear or coping strategies, and uncover overlooked aspects related to emotional dimensions, including bodily and metaphorical expressions.

Our sample of studies was quite heterogeneous, in terms of number of participants and their characteristics, and data collection methods. Although breast cancer was the most represented diagnosis, nearly half of the studies included other cancer diagnoses, and some studies explored cancer experiences within a specific culture (e.g. USA ethnic groups) or region (e.g. rural Scotland); nevertheless, in all the studies participants considered FCR to be an important concern. Interestingly, FCR was much represented in studies that were not directly studying it: even if not asked about, cancer patients spontaneously referred its presence, importance and impact. This idea is highlighted by previous reviews of FCR as a universal experience among cancer patients even if to varying degrees (Simard \& Savard, 2009).

In our review it was possible to find rich accounts of each of different dimensions of human experience: emotional, perceptual, cognitive, bodily and behavioral. The multidimensionality of FCR has been recognized from the earliest theoretical formulations (Lee-Jones, Humphris, Dixon, \& Hatcher, 1997; Fardell et al., 2016), and common aspects of the diverse explanatory theories of FCR include triggers, appraisal processes and the role of cognitions and beliefs, as well as behavioral/coping responses (Fardell et al., 2016; Simonelli et al., 2016). Apparently, emotional and bodily aspects have not been much explored yet.

Regarding the emotions revealed by the participants of the studies reviewed, fear was naturally central to most of peoples' experiences on FCR, but we could find other accompanying emotions as well, such as sadness, anger and very frequently undifferentiated negative states. Considered as adaptive emotions, fear relates to a situation of danger, sadness to a lived loss or psychological injury and anger to a situation of violation or attack on self (Greenberg \& Paivio, 1997). All these situations can be easily met in the cancer trajectory, particularly by the life-threatening nature of cancer, the various losses that the disease often carries and the sense of violation of physical and psychological integrity eventually brought by the disease itself or by its treatments. Those feelings can however be maladaptative, and if not adequately managed and regulated, can compromise successful adjustment to cancer experience (Conley, Bishop \& Andersen, 2016). Difficulties on emotion regulation can impact negatively on psychological and physical well-being (Brandão, 2017; Giese-Davis, Conrad, Nouriani, \& Spiegel, 2008). Psychotherapy can allow the exploration and differentiation of the different emotion states, especially the more undifferentiated ones, thus facilitating successful emotional processing (Pascual-Leone \& Greenberg, 2007).

Activators of the FCR experience were most commonly noticing something in one's own body, waiting for medical exams and results, encountering reminders such as talking or hearing about cancer, or simply thinking or remembering about cancer experience or a potential recurrence. External and internal triggers have actually been included in most theoretical approaches already developed for understanding FCR phenomenon (Fardell et al., 2016), but their frequency does not necessarily distinguish clinical from non-clinical FCR (Mutsaers et al., 2016).

The studies we have reviewed point to FCR not as a unique/simple fear, but 
rather suggest that it is a set of different fears for different people or even for the same person at different times. This finding is in line with the studies of Raymer (1993) and Vickberg (2001), in which cancer patients revealed different specific fears while talking about FCR (not always or uniquely of death). We can notice furthermore that some fears are about something known, such as going through certain treatments again, while others are about the unknown, such as the uncertainty of the disease course or death itself. This supports the distinction made between fear and anxiety (Elliott, 2013; Steimer, 2002), the former relating to a present or specific danger, the latter to a future or undefined danger. Considered as a main fear, the fear of death is, according to existential psychotherapy, one of humans' ultimate concerns and a source of natural anxiety, which can be catalyzed by the confrontation with the possibility of one's own death (Yalom, 1980). Death anxiety has been also considered a transdiagnostic construct (Iverach, Menzies, \& Menzies, 2014). The potential threat of death might connect to feelings of fear as well as sadness, as expressed by this participant in Berman's study (2013): "The sadness of thinking that I might not be there is horrifying; it really is". Fears of death, dependence, disfigurement, disruption and disability have previously been identified as common in cancer patients (e.g. Lesko, 1998).

Although there were a multiplicity of experiences regarding when, how and how long this experience endures, FCR tended to be described by participants from different studies as being always present, or in the back of the mind, and existing since having had the cancer diagnosis. Daily recurrent thoughts and duration of 30 minutes or more have been identified as possible features of clinical FCR (Mutsaers et al., 2016), but it was not possible in our review to distinguish different levels of FCR in participants.

While describing FCR, certain episodic memories were recalled by participants and might act as internal triggers for FCR, possibly stemming from traumatic experiences during the illness trajectory. FCR has been associated with post-traumatic stress disorder (PTSD) symptoms (Black \& White, 2005; Simard et al., 2013). According to DSM-V, we can find some criteria of PTSD in patient discourses in our review, such as re-experiencing of aspects of traumatic cancer-related events, in the form of flashbacks, emotional distress or physical reactivity after exposure to trauma reminders; avoidance of trauma-related stimuli; negative thoughts or feelings after the trauma; and trauma-related arousal and reactivity, including hypervigilance, heightened startle reaction or difficulty sleeping (APA, 2013). This could orient therapists towards recognizing and treating traumatic responses, when treating clinical FCR.

People expressed FCR by different means, either verbally or bodily. Metaphors were frequently used as mental representations of the FCR experience, following Lakoff \& Johnson's (2003) idea that metaphors structure what we think and understand, as well as our actions. It can also retain indescribable aspects of extremely difficult experiences (Berman, 2013). Our categorization of the metaphors resembles some of the conceptual metaphors for fear described by Kövecses (1990), from which we present some possible matches: FEAR IS AN OPPONENT IN A STRUGGLE (Kövecses, 1990), parallels our categories "adversarial situations" and "being in a war"; FEAR IS A HIDDEN ENEMY (Kövecses, 1990) fits our "under the surface"; FEAR IS AN ILLNESS (Kövecses, 1990) goes with "injury/illness"; FEAR IS A SUPERNATURAL BEING (Kövecses, 1990) fits "being attacked by monsters". We also noticed that descriptions or metaphors about FCR were inseparable from patient's views/metaphors about cancer itself: the above conceptual metaphors for fear might actually overlap with cancer metaphors cancer as an opponent in a struggle; cancer as a hidden enemy; cancer as an illness; cancer as a supernatural being. A meta-synthesis about cancer fears in the general population also found a core view of cancer as a vicious, unpredictable and 
indestructible enemy (Vrinten et al., 2017). Metaphors can help symbolize experiences in psychotherapy, and even can be used for tracking therapeutic change (Levitt, Korman, \& Angus, 2000).

Certain verbs and verb tenses revealed different mental activities related to FCR. The common subjunctive grammatical modes can easily recall the uncertainty experienced by cancer survivors (e.g. Elmir, Jackson, Beale, \& Schmied, 2010; Scott, 2014) and the role of tolerance of uncertainty (for a review of the concept, see Hillen, Gutheil, Strout, Smets, \& Han, 2017) as related to FCR (Fardell et al., 2016). Yet, the cognitive activity also reflected the embodied mind (Lakoff \& Johnson, 1999) and its sensory activities, such as when participants used visual or somatic terms (as seeing or feeling). Some bodily-expressive elements can be seen simultaneously as direct and metaphorical expressions, as when people refer shivering or being paralyzed by fear, whilst others are direct bodily expressions, as when people cried during the interviews when expressing sadness. Body-oriented therapeutic strategies, as focusing or clearing a space, have been used with cancer patients (Katonah \& Flaxman, 1991; Lennox \& Summers, 2010) and could be explored for helping people dealing with FCR.

Responding to FCR appeared to be a challenging task, and people either showed efforts to face the possibility of recurrence and their fear itself or else avoided the experience of FCR or its activators; this resembles the engagement versus disengagement coping strategies found in other studies (e.g. Conley, Bishop, \& Andersen, 2016) but also the biological responses of fight or flight before a dangerous situation. It was also possible to find conflict or ambivalence between these two opposing action tendencies, making it difficult in assess the adaptive value of each of these responses, and pointing to an internal motivational conflict over learned maladaptive responses to traumatic aspects of the cancer experience. It's interesting to note that in the general population, greater familiarity with cancer has been shown to increase fear, while a greater distance diminished it and brought a sense of safety to people (Vrinten et al., 2017).

Although the experts in the field of FCR have suggested maladaptive coping (exemplified by avoidance, reassurance seeking and body checking) as a possible characteristic of clinical FCR (Lebel et al., 2016), Mutsaers and colleagues (2016) failed to find a difference in coping strategies between clinical from non-clinical FCR (Mutsaers et al., 2016). As considered generally for the anxiety problems, possibly the main issue is how much distress the avoidance process brings the person and how much it disturbs his/her life functioning or goals, since the avoidance can affect not only the feared situations/triggers but also may involve avoiding the internal painful emotional experiences as well (Behar, DiMarco, Hekler, Mohlman, \& Staples, 2009; Elliott, 2013). The fear of emotional pain and its avoidance are recognized by different therapeutic approaches as hampering the processing of difficult experiences (Timulak \& Pascual-Leone, 2014) in psychotherapy.

Our exploration of the range of different expressions and meanings of FCR for cancer patients can bring some more insights for oncology clinical practice in general and specifically for psychotherapeutic practice. The different dimensions revealed support a wider perspective on the human experience of FCR, reinforcing the importance of humanizing health care by considering the person as a whole and simultaneously attending to the different dimensions of his/her experience. This can inform more effective communication between health care professionals and patients. Regarding therapeutic interventions, the cognitive-behavioral paradigm has so far been the main framework for approaching FCR (Fardell et al., 2016), but other possible lenses of understanding and treating FCR, such as supportive-experiential (Herschbach 
et al., 2010) or supportive therapies (Simonelli et al., 2016), have been also suggested. FCR can be seen as a problematic experience that needs to be assimilated (Stiles et al., 1990) through an emotional deepening process (Pascual-Leone \& Greenberg, 2007; Timulak \& Pascual-Leone, 2014). This can be done first through the differentiation of negative emotional states from global to specific, followed by exploration of secondary or defensive reactions (e.g., fear of fear) to find the underlying primary emotions, some of which are maladaptive (e.g., trauma-based fear or shame) and need to be transformed into adaptive emotions with corresponding adaptive actions. From this point of view, non-clinical FCR is likely to an adaptive emotional response, related to the real threat of a recurrence, leading to adaptive needs and actions of protection and surveillance. On the other hand, a dysfunctional FCR might be initially experienced as an (more or less) undifferentiated fear-based emotion or a secondary fear of fear or an avoidant emotional numbing. These might eventually be related to past traumatic events that cause high distress when they break through. The Cancer Australia review (2011) on FCR found, on one hand, a relationship between FCR and increased screening, prevention behaviors and increased contact with the health system and, on the other hand, an association between FCR and previous anxiety or PTSD (Cancer Australia, 2011). The main point that we draw, however, is that FCR is highly diverse, requiring that psychotherapy proceed from the exploration of specific meanings of FCR for each patient.

The dimensions examined in this review encourage more research on therapeutic approaches in addition to cognitive-behavioral for treating clinical FCR, as more light has been brought to aspects less explored so far in the literature on FCR, including emotional or bodily features. Taking also into account the theoretical orientation of most of our research team, we believe psychotherapies oriented to emotional and experiential aspects (as EFT or in general humanistic-experiential therapies), could be explored as a possible alternative.

Methodological Issues. Our team's choice of using only participants' direct quotations was congruent with our main goal of trying to know people's experience on FCR using their own "voice" and also with striving to respect the qualitative nature of the studies analysed. Nevertheless, being a secondary analysis, the data of our review was a potentially biased collection of published excerpts selected by the original authors.

We consider our selection of studies somehow too diverse, characterized by very different objectives and a huge and heterogeneous amount of information, which made the analysis more difficult. Notwithstanding, this made it possible to examine the presence of FCR in a variety of samples and types of studies, finding similar aspects of this experience independent of the goal of the study. Another limitation is the impossibility of distinguishing non-clinical from clinical FCR in the selected studies, which could be quite important for psychotherapeutic purposes.

Organizing our data around the emotion scheme structure can as well be questioned as arbitrary, but we consider this as a valid option for analysing the gathered information, which allowed us to explore FCR as an emotional experience, reflecting simultaneously our theoretical assumptions from a constructivist-interpretivist stance (Ponterotto, 2005) and our specific allegiance to Emotion-Focused Therapy.

Considering the therapeutic utility of this review, we note that the emotion scheme elements are nevertheless recognizable as core aspects of the human experience, and therefore potentially useful within any psychotherapeutic approach.

Considering the qualitative nature of this systematic review, we carried out and audited our analysis carefully, including following clear criteria for the studies to be included in the analysis. (We also followed recent recommendations for qualitative 
research; see Levitt, Motulsky, Wertz, Morrow, \& Ponterotto, 2017.) Even taking into account the goals of reviewing and synthesizing, we particularly realized the difficulty of maintaining the principle of contextualization of data (Levitt, Motulsky, Wertz, Morrow, \& Ponterotto, 2017). Therefore, the general results we presented might not fit exactly specific samples or participants with different ages, different cancer diagnoses, cultural backgrounds, or nationalities; instead, we have tentatively approached possible common or main features consistent across different samples.

\section{Conclusion}

Using direct words from cancer survivors, data obtained for this systematic review reinforced FCR as a concern with major impact in people's lives. Beyond aspects such as triggers, cognitions and coping behaviors, more clearly defined in previous work, we could also find different emotions related to FCR experience, particularly episodic memories evoked by it, bodily expressions, metaphors and distinct dimensions of mental activities, not so focused till now in the literature. The nature of patients' descriptions in the different domains points towards trauma-like experiences, especially re-experiencing, avoidance and hyperarousal aspects.

FCR is not an isolated phenomenon in the person's experience, but strongly affects all aspects of their experience: perceptions, emotions, bodily experiences, cognitions and behavior/motivation, making it a complex human experience. Focusing on FCR as an emotional experience that aggregates those different aspects brings a novel perspective to this overview of the FCR literature. We believe this perspective can positively contribute to it, encompassing and valuing aspects so far not so studied. Thus, in helping clients address their fear of cancer recurrence therapists need to work holistically and comprehensively with all aspects of the person. In this sense, humanistic-experiential psychotherapies can offer a promising approach to clinical FCR, for further investigation.

\section{References}

Allen, J. D., Savadatti, S., \& Levy, A. G. (2009). The transition from breast cancer "patient" to "survivor." Psycho-Oncology, 18(1), 71-78. https://doi.org/10.1002/pon.1380

Almeida, S., Silva, E., Sales, C., \& Elliott, R. (2016). Systematic Literature Review and Meta-synthesis of patients' experience on fear of cancer recurrence. PsychoOncology, 25(Suppl.3), 114. https://doi.org/10.1002/pon.4272

APA. (2013). DSM-V. Diagnostic and Statistical Manual of Mental Disorders (5th ed.). Washington, D. C.: American Psychiatric Association.

Arnold, E. M. (1999). The cessation of cancer treatment as a crisis. Social Work in Health Care, 29(2), 21-38. https://doi.org/10.1300/J010v29n02

Balmer, C., Griffiths, F., \& Dunn, J. (2015). A "new normal": Exploring the disruption of a poor prognostic cancer diagnosis using interviews and participant-produced photographs. Health: An Interdisciplinary Journal for the Social Study of Health, Illness and Medicine, 19(5), 451-472. https://doi.org/10.1177/1363459314554319

Bates, M. J. (1989). The Design of Browsing and Berrypicking Techniques. Retrieved from https://campusvirtual2.ub.edu/mod/resource/view.php?id=13839

Behar, E., DiMarco, I. D., Hekler, E. B., Mohlman, J., \& Staples, A. M. (2009). Current theoretical models of generalized anxiety disorder (GAD): Conceptual review and treatment implications. Journal of Anxiety Disorders, 23(8), 1011-1023. https://doi.org/10.1016/j.janxdis.2009.07.006 
Berman, M. B. (2013). The Experience of Fear of Cancer Recurrence Among EarlyStage Breast Cancer Survivors (doctoral dissertation). Wright Institute Graduate School of Psychology, USA.

Black, E. K., \& White, C. A. (2005). Fear of recurrence, sense of coherence and posttraumatic stress disorder in haematological cancer survivors. PsychoOncology, 14(6), 510-515. https://doi.org/10.1002/pon.894

Brandão, T. (2017). Adaptation to breast cancer: exploring the role of attachment and emotion regulation processes (doctoral dissertation). University of Porto, Portugal.

Brooks, C., Poudrier, J., \& Thomas, R. (2014). Visually depicting cancer fears: beyond biomedical concerns. Aporia, 6(3), 7-21.

Cancer Australia. (2011). The impact of fear of cancer recurrence on wellness: a systematic literature review. https://doi.org/http://dx.doi.org/10.1111/ajco.12144

Cesario, S. K., Nelson, L. S., Broxson, A., \& Cesario, A. L. (2010). Sword of Damocles cutting through the life stages of women with ovarian cancer. Oncology Nursing Forum, 37(5), 609-617. https://doi.org/10.1188/10.ONF.609-617

Cohen, M. Z., \& Ley, C. D. (2000). Bone marrow transplantation: the battle for hope in the face of fear. Oncology Nursing Forum, 27(3), 473-480.

Conley, C., Bishop, B., \& Andersen, B. (2016). Emotions and Emotion Regulation in Breast Cancer Survivorship. Healthcare, 4(3), 56. https://doi.org/10.3390/healthcare4030056

Crist, J. V, \& Grunfeld, E. A. (2013). Factors reported to influence fear of recurrence in cancer patients: a systematic review. Psycho-Oncology, 978-986. https://doi.org/10.1002/pon.3114

Crouch, M., \& McKenzie, H. (2000). Social realities of loss and suffering following mastectomy. Health: An Interdisciplinary Journal for the Social Study of Health, Illness and Medicine, 4(2), 196-215. https://doi.org/10.1177/136345930000400204

De Vries, J., Den Oudsten, B. L., Jacobs, P. M. E. P., \& Roukema, J. a. (2014). How breast cancer survivors cope with fear of recurrence: A focus group study. Supportive Care in Cancer, 22(3), 705-712. https://doi.org/10.1007/s00520-0132025-y

Denzin, N. K., \& Lincoln, Y. S. (2017). The SAGE Handbook of Qualitative Research (Fifth Edit). Sage Publications.

Elliott, R. (2006). Decoding Insight Talk: Discourse Analyses of Insight in Ordinary Language and in Psychotherapy. In L. G. Castonguay \& C. E. Hill (Eds.), Insight in Psychotherapy (pp. 167-185). Washington, D. C.: APA.

Elliott, R. (2013). Person-centered / experiential psychotherapy for anxiety difficulties : Theory, research and practice. Person-Centered \& Experiential Psychotherapies, $12(1), 16-32$.

Elliott, R., Fischer, C. T., \& Rennie, D. L. (1999). Evolving guidelines for publication of qualitative research studies in psychology and related fields. The British Journal of Cinical Psychology, 38, 215-229. https://doi.org/10.1348/014466599162782

Elliott, R., Watson, J. C., Goldman, R. N., \& Greenberg, L. S. (2004). Learning Emotion-Focused Therapy: The process-experiential approach to change. Washington, D. C.: American Psychological Association.

Elmir, R., Jackson, D., Beale, B., \& Schmied, V. (2010). Against all odds: Australian women's experiences of recovery from breast cancer. Journal of Clinical Nursing, 19(17-18), 2531-2538. https://doi.org/10.1111/j.1365-2702.2010.03196.x

Fang, S.-Y., \& Lee, K.-T. (2016). “From Patient to Survivor": Women's Experience With Breast Cancer After 5 Years. Cancer Nursing, 39(3), E40-8. 
https://doi.org/10.1097/NCC.0000000000000283

Fardell, J. E., Thewes, B., Turner, J., Gilchrist, J., Sharpe, L., Smith, A. “Ben,” ... Butow, P. (2016). Fear of cancer recurrence: a theoretical review and novel cognitive processing formulation. Journal of Cancer Survivorship : Research and Practice. https://doi.org/10.1007/s11764-015-0512-5

Flynn, K. E., Shelby, R. A., Mitchell, S. A., Fawzy, M. R., Hardy, N. C., Husain, A. M., ... Weinfurt, K. P. (2010). Sleep-wake functioning along the cancer continuum: focus group results from the Patient-Reported Outcomes Measurement Information System (PROMIS((R))). Psycho-Oncology, 19(10), 1086-1093. https://doi.org/10.1002/pon.1664

Giese-Davis, J., Conrad, A., Nouriani, B., \& Spiegel, D. (2008). Exploring emotionregulation and autonomic physiology in metastatic breast cancer patients: Repression, suppression, and restraint of hostility. Personality and Individual Differences, 44(1), 226-237. https://doi.org/10.1016/j.paid.2007.08.002

Greenberg, L. S., \& Paivio, S. C. (1997). Working with emotions in psychotherapy. New York: Guilford Press.

Greenberg, L. S., Rice, L. N., \& Elliott, R. (1993). Facilitating emotional change: The moment-by-moment process. New York: Guilford Press.

Greenberg, L. S., \& Watson, J. C. (2006). Emotion Focused Therapy for Depression. Washington, D. C.: APA. Retrieved from papers2://publication/uuid/EB5A314E0610-4893-8062-60BBF6976613

Grimsbø, G. H., Finset, A., \& Ruland, C. M. (2011). Left hanging in the air: experiences of living with cancer as expressed through e-mail communications with oncology nurses. Cancer Nursing, 34(2), 107-116 10p. https://doi.org/10.1097/NCC.0b013e3181eff008

Hall, L. K., Kunz, B. F., Davis, E. V, Dawson, R. I., \& Powers, R. S. (2015). The Cancer Experience Map: An Approach to Including the Patient Voice in Supportive Care Solutions. Journal of Medical Internet Research, 17(5), e132. https://doi.org/10.2196/jmir.3652

Herschbach, P., Book, K., Dinkel, A., Berg, P., Waadt, S., Duran, G., ... Henrich, G. (2010). Evaluation of two group therapies to reduce fear of progression in cancer patients. Supportive Care in Cancer, 18(4), 471-479. https://doi.org/10.1007/s00520-009-0696-1

Herschbach, P., \& Dinkel, A. (2014). Fear of progression. Recent Results in Cancer Research. Fortschritte Der Krebsforschung. Progres Dans Les Recherches Sur Le Cancer, 197, 11-29. https://doi.org/10.1007/978-3-642-40187-9_2

Hillen, M. A., Gutheil, C. M., Strout, T. D., Smets, E. M. A., \& Han, P. K. J. (2017). Tolerance of uncertainty: Conceptual analysis, integrative model, and implications for healthcare. Social Science and Medicine, 180, 62-75. https://doi.org/10.1016/j.socscimed.2017.03.024

Horlick-Jones, T. (2011). Understanding fear of cancer recurrence in terms of damage to "everyday health competence". Sociology of Health \& Illness, 33(6), 884-898. https://doi.org/10.1111/j.1467-9566.2010.01325.x

Iverach, L., Menzies, R. G., \& Menzies, R. E. (2014). Death anxiety and its role in psychopathology: Reviewing the status of a transdiagnostic construct. Clinical Psychology Review, 34(7), 580-593. https://doi.org/10.1016/j.cpr.2014.09.002

Jones, W. C. (2012). Quality of life after cancer treatment: A mixed methods investigation of predictors of distress in leukemia and lymphoma survivors in Colorado (doctoral dissertation). University of Colorado, USA.

Kaba, R., \& Sooriakumaran, P. (2007). The evolution of the doctor-patient relationship. 
International Journal of Surgery, 5(1), 57-65.

https://doi.org/10.1016/j.ijsu.2006.01.005

Katonah, D. G., \& Flaxman, J. (1991). Focusing: An Adjunct Treatment for Adaptive

Recovery from Cancer. Retrieved November 29, 2017, from

http://www.focusing.org/adjunct_treatment.html

Kelly, M., \& Dowling, M. (2011). Patients' lived experience of myeloma. Nursing

Standard (Royal College of Nursing (Great Britain) : 1987), 25(28), 38-44. https://doi.org/10.7748/ns2011.03.25.28.38.c8397

Kövecses, Z. (1990). Emotion concepts. Psycnet.Apa.Org. https://doi.org/10.1007/978$1-4612-3312-1$

Kvale, E. A., Meneses, K., Demark-Wahnefried, W., Bakitas, M., \& Ritchie, C. (2015). Formative research in the development of a care transition intervention in breast cancer survivors. European Journal of Oncology Nursing, 19(4), 329-335. https://doi.org/10.1016/j.ejon.2015.01.010

Lakoff, G., \& Johnson, M. (1999). Philosophy in the flesh: The embodied mind and its challenge to western thought. NY: Basic Books.

Lakoff, G., \& Johnson, M. (2003). Metaphors we live by. Journal of Philosophy. London: The University of Chicago Press.

Lebel, S., Ozakinci, G., Humphris, G., Mutsaers, B., Thewes, B., Prins, J., ... Butow, P. (2016). From normal response to clinical problem: definition and clinical features of fear of cancer recurrence. Supportive Care in Cancer, 24(8), 3265-3268. https://doi.org/10.1007/s00520-016-3272-5

Lee-Jones, C., Humphris, G., Dixon, R., \& Hatcher, M. B. (1997). Fear of Cancer Recurrence - A literature review and proposed cognitive formulation to explain exacerbation of recurrence fears. Psycho-Oncology, 6, 95-105.

Lennox, S. L., \& Summers, L. (2010). Effect of "Clearing a Space " on Quality of Life in Women with Breast Cancer Joan Klagsbrun, 9(2), 48-53.

Lesko, L. M. (1998). Hematopoietic Dyscrasias. In J. C. Holland (Ed.), Psychooncology (pp. 406-416). New York; Oxford: Oxford University Press.

Levitt, H., Korman, Y., \& Angus, L. (2000). A metaphor analysis in treatments of depression: Metaphor as a marker of change. Counselling Psychology Quarterly, 13(1), 23-35. https://doi.org/10.1080/09515070050011042

Levitt, H. M., Motulsky, S. L., Wertz, F. J., Morrow, S. L., \& Ponterotto, J. G. (2017). Recommendations for Designing and Reviewing Qualitative Research in Psychology : Promoting Methodological Integrity. Qualitative Psychology, 4(1), 222.

Longtin, Y., Sax, H., Leape, L. L., Sheridan, S. E., Donaldson, L., \& Pittet, D. (2010). Patient participation: current knowledge and applicability to patient safety. Mayo Clinic Proceedings., 85(1), 53-62. https://doi.org/10.4065/mcp.2009.0248

McHugh, M. L. (2012). Interrater reliability: the kappa statistic. Biochem Med (Zagreb), 22(3), 276-282.

McLoone, J., Watts, K., Menzies, S., Meiser, B., Butow, P., \& Kasparian, N. (2012). When the risks are high: psychological adjustment among melanoma survivors at high risk of developing new primary disease. Qualitative Health Research, 22(8), 1102-1113. https://doi.org/10.1177/1049732312448542

Mead, N., \& Bower, P. (2000). Patient-centredness: a conceptual framework and review of the empirical literature. Social Science \& Medicine, 51(7), 1087-1110. https://doi.org/10.1016/S0277-9536(00)00098-8

Mehrabi, E., Hajian, S., Simbar, M., Hoshyari, M., \& Zayeri, F. (2016). The Lived Experience of Iranian Women Confronting Breast Cancer Diagnosis. Journal of 
Caring Sciences, 5(1), 43-55. https://doi.org/10.15171/jcs.2016.005

Mikkelsen, T. H., Søndergaard, J., Jensen, A. B., \& Olesen, F. (2008). Cancer rehabilitation: Psychosocial rehabilitation needs after discharge from hospital? A qualitative interview study. Scandinavian Journal of Primary Health Care, 26(4), 216-221. https://doi.org/10.1080/02813430802295610

Miller, L. E. (2015). Young Breast Cancer Survivors' Experiences of Uncertainty. Journal of Applied Communication Research, 43(4), 429-449. https://doi.org/10.1080/00909882.2015.1083600

Mutsaers, B., Jones, G., Rutkowski, N., Tomei, C., Séguin Leclair, C., PetriconeWestwood, D., ... Lebel, S. (2016). When fear of cancer recurrence becomes a clinical issue: a qualitative analysis of features associated with clinical fear of cancer recurrence. Supportive Care in Cancer, 24(10), 4207-4218. https://doi.org/10.1007/s00520-016-3248-5

NCI. (n.d.). Dictionary Cancer Terms. Retrieved November 16, 2017, from https://www.cancer.gov/publications/dictionaries/cancer-terms?search=survivor

NICE. (2012a). Methods for the development of NICE public health guidance (third edition). Retrieved from http://www.nice.org.uk/aboutnice/howwework/developingnicepublichealthguidanc e/\%5Cnpublichealthguidanceprocessandmethodguides/\%5Cnpublic_health_guidan ce_process_and_method_guides.jsp

NICE. (2012b). Service User Experience in Adult Mental Health: Improving the experience of care for people using adult NHS Mental Health Services. Retrieved from http://www.nice.org.uk/guidance/cg136

Pascual-Leone, A., \& Greenberg, L. S. (2007). Emotional processing in experiential therapy: Why "the only way out is through." Journal of Consulting and Clinical Psychology, 75(6), 875-887. https://doi.org/10.1037/0022-006X.75.6.875

Ponterotto, J. G. (2005). Qualitative Research in Counseling Psychology : A Primer on Research Paradigms and Philosophy of Science Qualitative Research in Counseling Psychology: A Primer on Research Paradigms and Philosophy of Science. Journal of Counseling Psychology, 52(June), 126-136. https://doi.org/10.1037/0022-0167.52.2.126

Raymer, D. (1993). On the fear of cancer recurrence (doctoral dissertation). University of Toronto, Canada.

Sadler-Gerhardt, C. (2007). "And then what happened?": the lived experiences of breast cancer survivors and theirs stories of change and meaning (doctoral dissertation). University of Akron, USA.

Salci, M. A., \& Marcon, S. S. (2010). A convivência com o fantasma do câncer. Revista Gaúcha Enfermagem, 31(1), 18-25. https://doi.org/10.1590/S198314472010000100003

Saraf, S., Singh, T. B., \& Khurana, S. (2013). Cervical cancer survivors: Meaning in life. Psychological Studies, 58(2), 144-152. https://doi.org/10.1007/s12646-0130186-x

Scott, E. (2014). A legacy of lingering uncertainty. The experience of long-term cancer survivorship: a multiple-case study (doctoral dissertation). University of Nottingham, UK.

Shachar Siman-Tov, E. (2008). The experience and the role of spirituality among women who have had breast cancer and who have completed their medical treatments (doctoral dissertation). University of Hartford, USA.

Sharpe, L., Thewes, B., \& Butow, P. (2017). Current directions in research and treatment of fear of cancer recurrence. Current Opinion in Supportive and 
Palliative Care, 11(3), 191-196. https://doi.org/10.1097/SPC.0000000000000288

Siegel, K., Gorey, E., \& Gluhoski, V. (1997). Pregnancy decision making among women previously treated for breast cancer. Journal of Psychosocial Oncology, 15(1), 1-14. https://doi.org/10.1300/J077v15n01

Simard, S., \& Savard, J. (2009). Fear of Cancer Recurrence Inventory: Development and initial validation of a multidimensional measure of fear of cancer recurrence. Supportive Care in Cancer, 17(3), 241-251. https://doi.org/10.1007/s00520-0080444-y

Simard, S., Thewes, B., Humphris, G., Dixon, M., Hayden, C., Mireskandari, S., \& Ozakinci, G. (2013). Fear of cancer recurrence in adult cancer survivors: a systematic review of quantitative studies. Journal of Cancer Survivorship : Research and Practice, 7(3), 300-322. https://doi.org/10.1007/s11764-013-0272-z

Simonelli, L. E., Siegel, S. D., \& Duffy, N. M. (2016). Fear of cancer recurrence : a theoretical review and its relevance for clinical presentation and management. Psycho-Oncology. https://doi.org/10.1002/pon.4168

Steimer, T. (2002). The biology of fear- and anxiety-related behaviors. Dialogues in Clinical Neuroscience, 4(3), 231-249. https://doi.org/10.1097/ALN.0b013e318212ba87

Stiles, W. B., Llewelyn, S. P., Firth-cozens, J. a, Margison, F. R., Shapiro, D. a, \& Hardy, G. (1990). Assimilation of problematic experiences by clients in psychotherapy. Psychotherapy, 27(3), 411-420. https://doi.org/10.1037/00333204.27.3.411

Strauss, A., \& Corbin, J. (2008). Basics of Qualitative Research: Techniques and Procedures for Developing Grounded Theory. Basics of Qualitative Research Grounded Theory Procedures and Techniques (Vol. 3). https://doi.org/10.4135/9781452230153

Taylor, C., Richardson, A., \& Cowley, S. (2011). Surviving cancer treatment: an investigation of the experience of fear about, and monitoring for, recurrence in patients following treatment for colorectal cancer. European Journal of Oncology Nursing : The Official Journal of European Oncology Nursing Society, 15(3), 243-249. https://doi.org/10.1016/j.ejon.2011.03.010

Taylor, S. J., Bogdan, R., \& DeVault, M. L. (2016). Introduction to qualitative research methods: A guidebook and resource. Hoboken, New Jersey: John Wiley \& Sons, Inc.

Thewes, B., Butow, P., Zachariae, R., Christensen, S., Simard, S., \& Gotay, C. (2012). Fear of cancer recurrence: a systematic literature review of self-report measures. Psycho-Oncology, 21(6), 571-587. https://doi.org/10.1002/pon.2070

Thewes, B., Lebel, S., Seguin Leclair, C., \& Butow, P. (2016). A qualitative exploration of fear of cancer recurrence (FCR) amongst Australian and Canadian breast cancer survivors. Supportive Care in Cancer : Official Journal of the Multinational Association of Supportive Care in Cancer, 24(5), 2269-2276. https://doi.org/10.1007/s00520-015-3025-x

Thomas-Maclean, R. L. (2001). Victims, Patients, Survivors, Women: Experiences of Embodiment after breast cancer (doctoral dissertation). The University of New Brunswick, Canada.

Thompson, C. A., Charlson, M. E., Schenkein, E., Wells, M. T., Furman, R. R., Elstrom, R., ... Leonard, J. P. (2010). Surveillance CT scans are a source of anxiety and fear of recurrence in long-term lymphoma survivors. Annals of Oncology: Official Journal of the European Society for Medical Oncology / ESMO, 21(11), 2262-2266. https://doi.org/10.1093/annonc/mdq215 
Timulak, L. (2009). Meta-analysis of qualitative studies: a tool for reviewing qualitative research findings in psychotherapy. Psychotherapy Research: Journal of the Society for Psychotherapy Research, 19(4-5), 591-600. https://doi.org/10.1080/10503300802477989

Timulak, L., \& Pascual-leone, A. (2014). New Developments for Case Conceptualization in Emotion-Focused Therapy. https://doi.org/10.1002/cpp.1922

Vickberg, S. M. J. (2001). Fears about Breast Cancer Recurrence: Interviews with a diverse sample. Cancer Practice, 9(5), 237-243.

Vrinten, C., McGregor, L. M., Heinrich, M., von Wagner, C., Waller, J., Wardle, J., \& Black, G. B. (2017). What do people fear about cancer? A systematic review and meta-synthesis of cancer fears in the general population. Psycho-Oncology, 26(8), 1070-1079. https://doi.org/10.1002/pon.4287

Wang, J. W., Shen, Q., Ding, N., Zhang, T. R., Yang, Z. Q., Liu, C., ... Yu, J. M. (2016). A qualitative exploration of the unmet psychosocial rehabilitation needs of cancer survivors in China. Psycho-Oncology, 912(November 2015), 905-912. https://doi.org/10.1002/pon.4023

Yalom, I. D. (1980). Existential Psychotherapy. New York: Basic Books. 
Table 1. Characteristics of the selected studies

\begin{tabular}{|l|l|}
\hline Articles & $54(84 \%)$ \\
\hline Dissertations & $10(16 \%)$ \\
\hline Studies exclusively qualitative & $60(94 \%)$ \\
\hline Mixed qualitative/quantitative studies & $4(6 \%)$ \\
\hline Data Collection method & \\
\hline Individual interviews & $46(72 \%)$ \\
\hline Focus group interviews & $11(17 \%)$ \\
\hline Mixed qualitative methods & $3(5 \%)$ \\
\hline Other methods & $4(6 \%)$ \\
\hline Total participants & $1727($ range $1-360)$ \\
\hline Mean (median) per study & $28(16)$ \\
\hline Standard Deviation & 47 \\
\hline Diagnosis & Number of studies $(\%)$ \\
\hline Breast & $34(53 \%)$ \\
\hline Mixed diagnosis & $16(25 \%)$ \\
\hline Gynecological & $7(11 \%)$ \\
\hline Blood cancers (leukemia, lymphoma, myeloma) & $4(6 \%)$ \\
\hline Others (colorectal; head and neck and melanoma) & $3(5 \%)$ \\
\hline Countries & \\
\hline USA & $26(41 \%)$ \\
\hline UK & $9(14 \%)$ \\
\hline Australia & $6(9 \%)$ \\
\hline Canada & $6(9 \%)$ \\
\hline Scandinavia (Denmark, Norway, Sweden) & $5(8 \%)$ \\
\hline Brazil & $3(5 \%)$ \\
\hline Others & $6(9 \%)$ \\
\hline Mixed countries & $3(5 \%)$ \\
\hline Year of publication & Number of studies \\
\hline 1992-1999 & $7(11 \%)$ \\
\hline $2000-2009$ & $22(34 \%)$ \\
\hline $2010-2016$ & $35(55 \%)$ \\
\hline & \\
\hline
\end{tabular}


Figure 1. PRISMA flow diagram of the study review

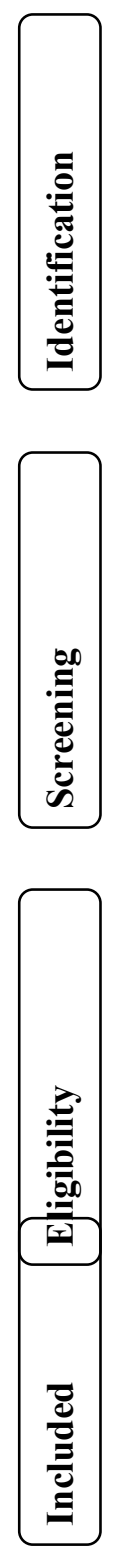

Records identified through database
searching
$(\mathrm{n}=3312)$

$(\mathrm{n}=3312)$
Additional records identified through other sources $(\mathrm{n}=7)$

Records screened after duplicates removed

$$
(\mathrm{n}=2414)
$$

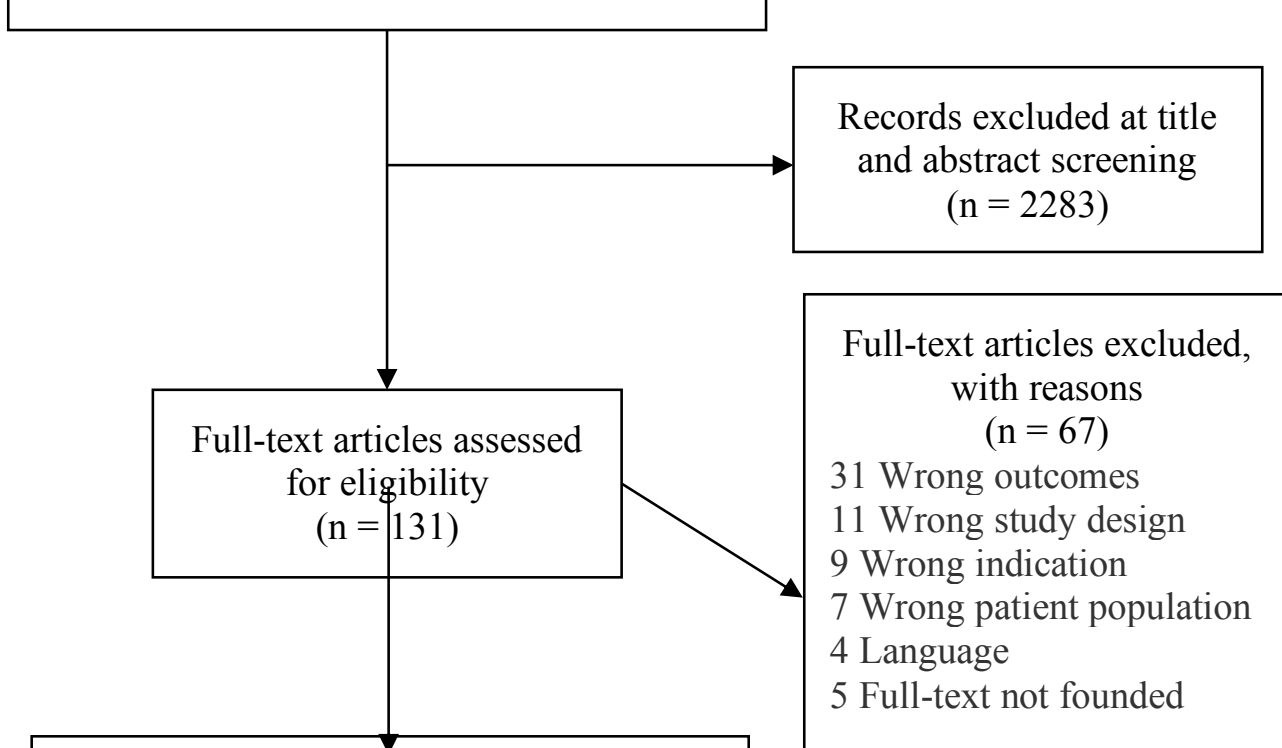

Studies included in qualitative synthesis

$$
(n=64)
$$

$\mathrm{N}=8$ FCR primary focus/goal $\mathrm{N}=56$ FCR emerging/related theme 


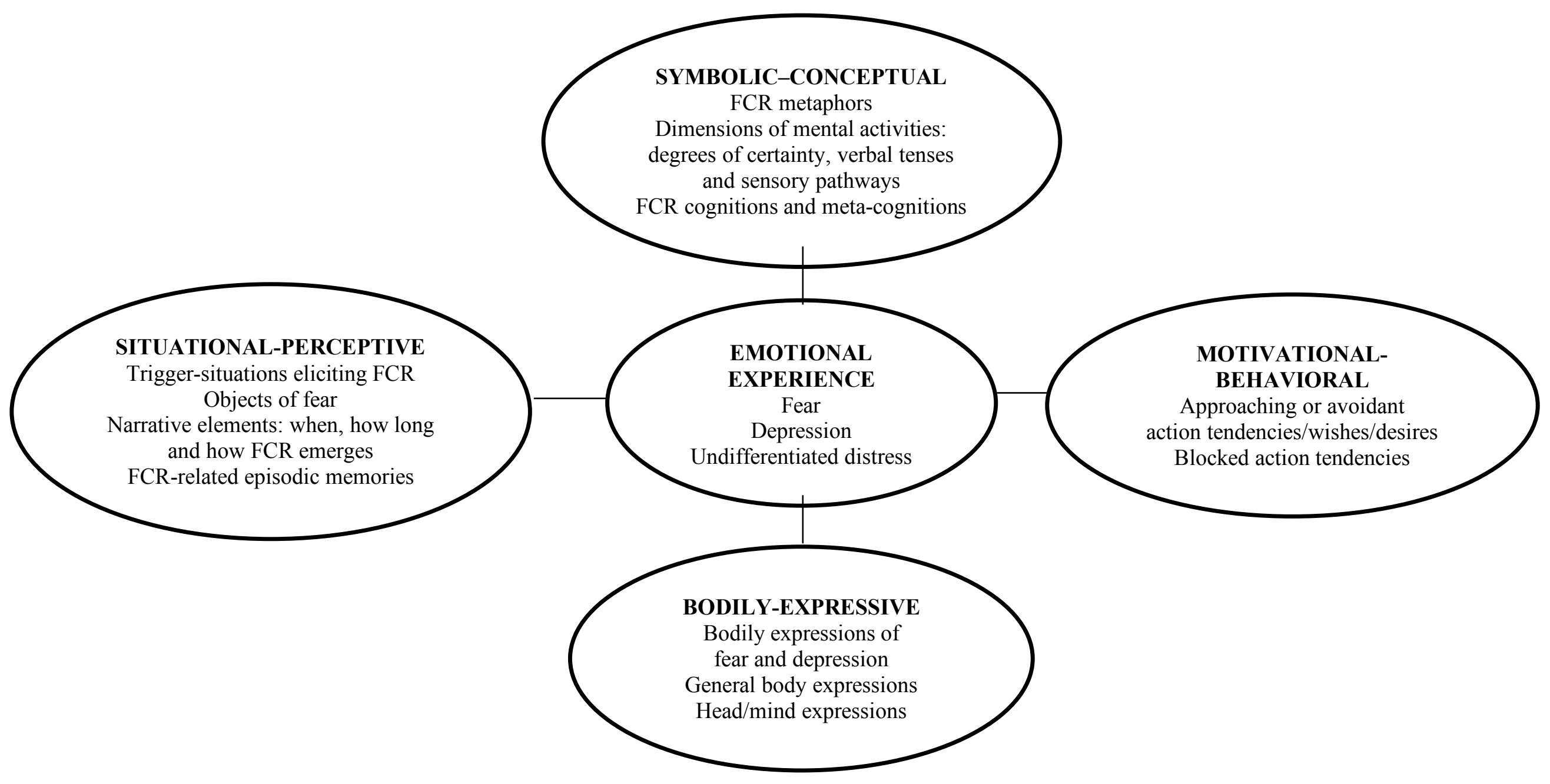

Figure 2. Synthesis of the high-level results according to the emotion scheme framework (adapted from Elliott et al, 2004) 
Figure 3. Dimensions of mental activities found in the analysis of the studies

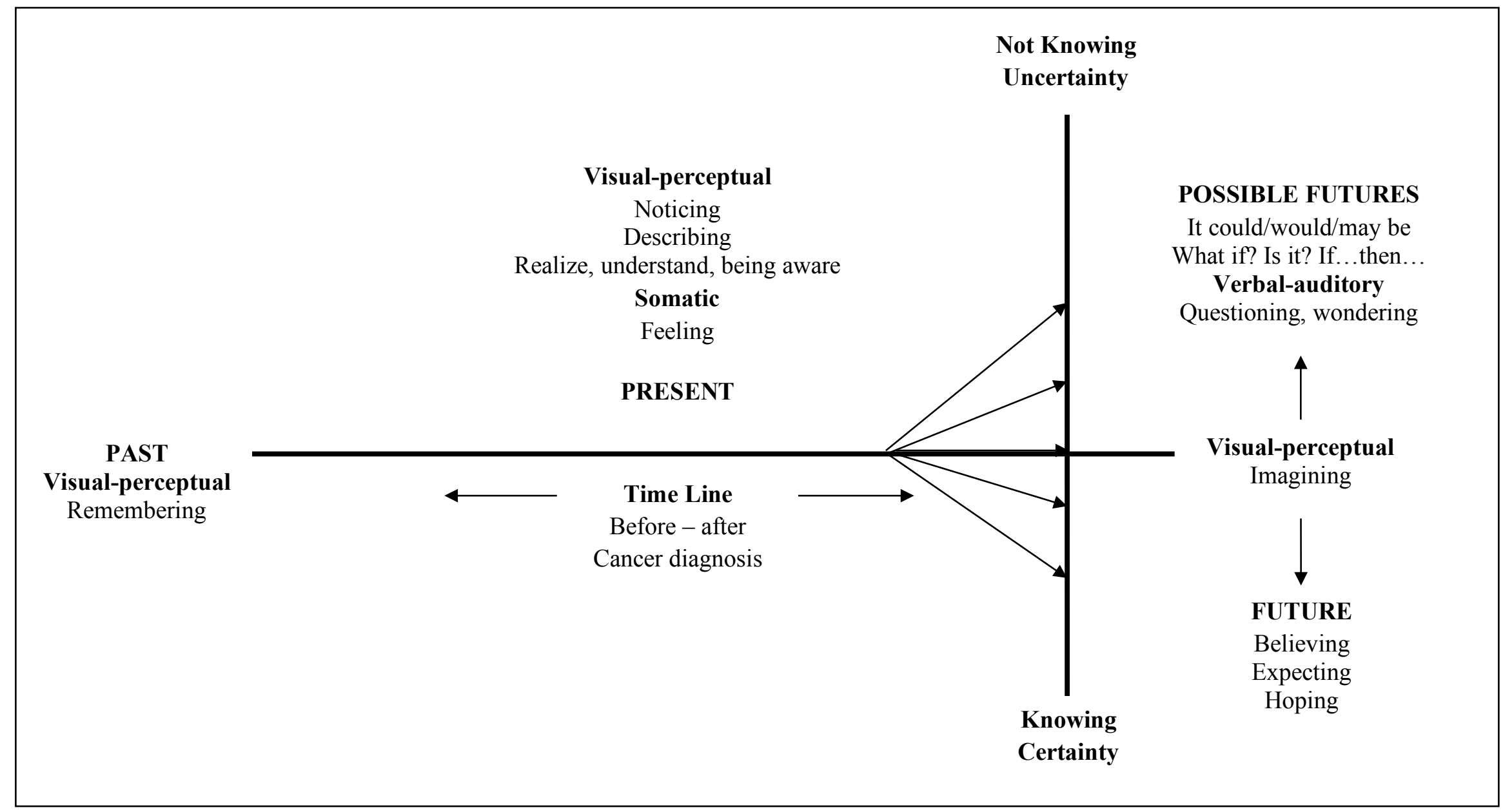

